\title{
Erratum
}

\section{American and Portuguese perspectives on transition from parents focus group}

Lúcia Canha, Laura A. Owens, Celeste Simões and Margarida Gaspar de Matos

[Journal of Vocational Rehabilitation 38 (2013), 195-205]

The third paragraph on page 197 should be preceded by the statement that appeared previously on page 196 to more accurately read:

As adults, they are supported under the Decree Law No. 290 of 2009 (DL No. 290/2009) that creates programs for Employment and Support Qualification through the Institute of Employment and Vocational Training (IFP). It is a law administered by Labor and Social Solidarity Ministry and defines the system for granting technical and financial support to develop employment policies and the qualifications and certification for employment support professionals.

The subtitle on page 199 "Student-focused individualized planning" should be preceded by the title "5.2 Transition preparation for post-school life". All the following subtitles should acquire the numbering 5.2.1, 5.2.2, 5.2.3, 5.2.4. 